\title{
Recurrence Rates and Characteristics of Phyllodes Tumors Diagnosed by Ultrasound-guided Vacuum-assisted Breast Biopsy (VABB)
}

\author{
HAI-LIN PARK ${ }^{1}$, YOUNG CHAN PYO ${ }^{1}$, KA YOUNG KIM ${ }^{1}$, JONG SEOB PARK ${ }^{1}$, JI-EUN SHIN ${ }^{2}$, \\ HYE-RIN KIM ${ }^{2}$, BORA YANG ${ }^{2}$, JI-YOUNG KIM ${ }^{3}$, JEONG YUN SHIM ${ }^{3}$, EUN-AH SHIN ${ }^{3}$ and SONG-MI NOH ${ }^{3}$ \\ Departments of ${ }^{1}$ Surgery, ${ }^{2}$ Diagnostic Radiology, and ${ }^{3}$ Diagnostic Pathology, \\ Gangnam CHA Medical Center, College of Medicine, CHA University, Seoul, Republic of Korea
}

\begin{abstract}
Background/Aim: Recently, the development of ultrasonography (US)-guided vacuum-assisted breast biopsy (VABB) has enabled the excision of benign breast tumors with normal surrounding breast tissues; thus, complete excision is possible without residual tumor tissue. We sought to identify the clinicopathological characteristics and recurrence rates of benign phyllodes tumors diagnosed by US-guided VABB. Patients and Methods: Data from 11,221 US-guided VABBs performed at the Gangnam Cha Medical Center over 12 years were analyzed. Eighty-three lesions were diagnosed as benign phyllodes tumors; 67 with $>24$ months of follow-up data were investigated. All lesions were excised using an 8-gauge probe without residual tissue; patients underwent follow-up US every 3-6 months. Results: Five patients (7.46\%) experienced local recurrence during a mean follow-up period of 27.8 months; no distant metastases occurred. The mean tumor size was $3.0 \mathrm{~cm}$ in the recurrence group and $1.87 \mathrm{~cm}$ in the non-recurrence group ( $p=0.05)$. Conclusion: Benign phyllodes tumors excised and diagnosed using $V A B B$ showed a low recurrence rate during the follow-up period; thus, these tumors, particularly those $<3 \mathrm{~cm}$, can be safely monitored with ultrasonography instead of performing immediate re-excision.
\end{abstract}

Currently, the lifetime incidence risk of breast cancer in women of Western countries is 1 in 8 , while $60 \%$ develop benign breast diseases (1). The most common benign breast diseases are fibroadenomas and fibrocystic breast disease. Phyllodes tumors (PTs) are uncommon fibroepithelial lesions accounting

Correspondence to: Hai-Lin Park, Department of Surgery, Gangnam CHA Medical Center, College of Medicine, CHA University, Seoul, Republic of Korea. Tel: +82 234683206, Fax: +82 234682608, e-mail: phl1@cha.ac.kr, parkhl1018@gmail.com

Key Words: Benign phyllodes tumor, ultrasonography, mammotome excision, vacuum-assisted breast biopsy. for approximately $1 \%$ of all breast tumors (2). Unlike fibroadenomas, PTs show characteristic histological features of stromal hypercellularity and severe intracanalicular stromal growth, resulting in a leaf-shaped appearance. PTs were first described by Muller in 1838 as cystosarcoma phyllodes (3); however, in 1982, the World Health Organization (WHO) decided that PT was the most appropriate term since $70 \%$ of cases have a benign phase and very rarely undergo cystic changes (4). Although PTs are clinically similar to fibroadenomas, they are more common in younger individuals. Moreover, they are more likely to show clear margins with no calcification, a round or oval lobular appearance, a heterogeneous interior, and an internal cystic space on mammography or ultrasonography (US). Generally, PTs are classified as benign, borderline, or malignant based on the extent of cell mitosis under high-magnification microscopy. For treatment, wide local excision including at least a $1 \mathrm{~cm}$ margin from surrounding normal tissues is essential $(5,6)$; the incidence of local recurrence is $8-40 \%$ while that of distant metastasis is $1-21 \%$ (7-9). Prognosis based only on biopsy results may be unreliable, since metastasis has been reported even for tumors that were diagnosed histologically as benign; moreover, cases of malignant tumors with no recurrence or metastasis also exist $(5,10,11)$. Recently, the development of US-guided vacuum-assisted breast biopsy (VABB) has enabled the excision of benign breast tumors with normal surrounding breast tissues; complete excision is usually possible with no residual tumor tissue $(12,13)$. In this study, we investigated the long-term outcomes of patients with confirmed benign PT who underwent complete excision biopsy (and no subsequent surgery) using VABB and showed no residual tumors on US.

\section{Materials and Methods}

Patients. Among the 11,221 lesions from 8,748 patients that underwent diagnostic and therapeutic VABB (Mammotome ${ }^{\circledR}$; Devicor Medical Products, Inc., Cincinnati, OH, USA) between January 2003 and December 2015 at the Department of Surgery, 
Gangnam CHA Medical Center, 96 lesions were diagnosed as PTs on histopathological examinations. We conducted a retrospective analysis of these 96 lesions using medical records and histopathological data. The present study was performed with the approval of the Institutional Ethical committee of Gangnam CHA medical center (approval number, GCI 18-23). Informed consent was not required due to the retrospective nature of the study.

Of the 96 PTs diagnosed with VABB, 83 were benign, 9 were borderline, and 4 were malignant. The criteria for benign, borderline, and malignant PTs were $0-1,2-5$, and $\geq 6$ mitotic cells per microscopic field of view at $10 \times$ magnification. Wide excision was performed immediately for lesions diagnosed as borderline or malignant; of the 9 borderline cases, $6(75 \%)$ were histopathologically confirmed as residual borderline PT; none of these borderline cases were upgraded to malignant. Of the 4 widely excised malignant PTs, 1 (25\%) showed residual tumor tissue that was also confirmed to be malignant PT.

Of the 83 cases of benign PT, 13 were excluded because they were lost to follow up. Of the remaining 70 cases, we excluded 3 that underwent wide excision due to a suspected residual tumor on US during the first 3 postoperative months, and we investigated the remaining 67 cases (from 61 patients) for which at least 24 months of follow-up after VABB were available (Figure 1). Follow-up US was performed 3 months after the VABB procedure to check for the presence of a residual tumor; if there were no specific findings, US was performed every 6 months to check for new nodules at or near the VABB sites. Any new nodule was classified as a suspected recurrent lesion and VABB was repeated; lesion recurrence was confirmed by histological examination. The mean follow-up duration was $36.8 \pm 32.8$ months (range $=25-124$ months).

Indications for VABB were as follows: patients with Breast Imaging Reporting and Data System (BI-RADS) category 3 or 4 lesions who were not expected to be consistently available for followup, those who are planning to become pregnant, those experiencing severe anxiety regarding their lesions, those whose lesions grew during follow-up, and those complaining of pain or other symptoms. US-guided VABB was also performed on patients with a lesion size $\geq 3 \mathrm{~cm}$ who refused surgical excision over concerns about scarring. Moreover, even when a breast nodule was diagnosed as benign via core needle biopsy (CNB) or fine needle aspiration (FNA) cytology, VABB was additionally performed in cases of palpable lesions or imaging histologic discordance. Of the 96 cases diagnosed as PT through VABB in this study, 16 had undergone prior FNA or CNB, 14 of which had been diagnosed as another benign disease such as fibroadenoma while 2 were diagnosed as benign PT.

VABB was not performed on BI-RADS category 5 lesions. In patients with bleeding tendencies due to anticoagulant medication, such medications were temporarily stopped and the patients were tested for normal coagulation before they were considered for VABB. In pregnant or breastfeeding women, VABB was performed only when a biopsy was absolutely necessary.

VABB was performed in the operating room by a single surgeon under local anesthesia (1\% lidocaine with epinephrine) using an 8gauge needle via a $3-5 \mathrm{~mm}$ incision. The needle was rotated $45^{\circ}$ to both sides until the lesion was deemed completely excised on US. For hemostasis, direct pressure was applied for 5-10 min after the procedure; an adhesive elastic band was then attached, and the patient was instructed to rest in bed for a few hours.

Data and statistical analysis. The patients' age at the time of diagnosis was recorded. The lesion size on US was defined as its maximum diameter. The follow-up period was defined as that between the confirmation of a benign PT via US-guided VABB and the last clinical follow-up date. Recurrence was defined as the reappearance of a histologically confirmed tumor within the region of the previous excision. The interval to recurrence was defined as the duration between the date of US-guided VABB to that of the diagnosis of recurrence. Age, lesion size, palpability, and US-guided BI-RADS categories were compared between the benign, borderline, and malignant groups. The benign PTs were also classified into 'recurrence' and 'non-recurrence' groups during the follow-up period. The age, lesion size on US, palpability on physical examination, US-guided BI-RADS categories, follow-up period, and interval to recurrence were compared between these 2 groups.

Data were compared using Fisher's exact test for categorical variables, the Mann-Whitney $U$-test and Kruskal-Wallis test were used to compare continuous variables between 2 and 3 groups, respectively. Statistical analyses were performed using the SPSS statistical software version 21.0 (SPSS Inc, Chicago, IL). A p-value of $<0.05$ was considered statistically significant.

\section{Results}

Among all lesions that underwent VABB, 0.86\% (96/11221) were PTs. The mean age of patients diagnosed with PT was $32 \pm 9.8$ years. The mean age of patients with benign PT was $30 \pm 9.0$ years while those of patients with borderline and malignant PTs were $39 \pm 12.1$ and $39 \pm 13.8$ years, respectively, indicating that patients with benign PTs were slightly younger $(p=0.05)$.

The mean tumor sizes at the time of diagnosis were $1.97 \pm 0.84,2.32 \pm 1.28$, and $3.63 \pm 2.81 \mathrm{~cm}$ for benign, borderline, and malignant PTs, respectively, indicating that malignant lesions tended to be larger than their benign counterparts albeit not significantly. There were also no significant differences in lesion palpability or BI-RADS US category (Table I).

Among the 67 benign PTs, 11 underwent VABB for suspected recurrence during follow-up US examinations performed every 3-6 months. Of these, 5 were confirmed to be recurred PTs on pathological examinations while 6 were identified as other benign lesions such as fibroadenoma; thus, the overall recurrence rate was $7.46 \%$. The mean follow-up duration for the 5 recurred cases was 27.8 months (range $=10$ 47 months). The median age of the recurrence group was 25 years, which was younger than that of the non-recurrence group (30 years) although the difference was not significant $(p=0.192)$ (Table II). The mean tumor size in the recurrence group was $3.00 \pm 1.14 \mathrm{~cm}$ (range $=1.98-4.76 \mathrm{~cm}$ ), which was significantly larger than that in the non-recurrence group $(1.87 \pm 0.72 \mathrm{~cm}, p=0.027)$. All 5 lesions in the recurrence group were palpable compared to only $64.5 \%$ of those in the non-recurrence group, although the difference was not significant. No difference was also found in BI-RADS US classification between the recurrence and non-recurrence groups (Table II). The 5 recurrent cases are summarized in Table III; all underwent either VABB or wide excision and 


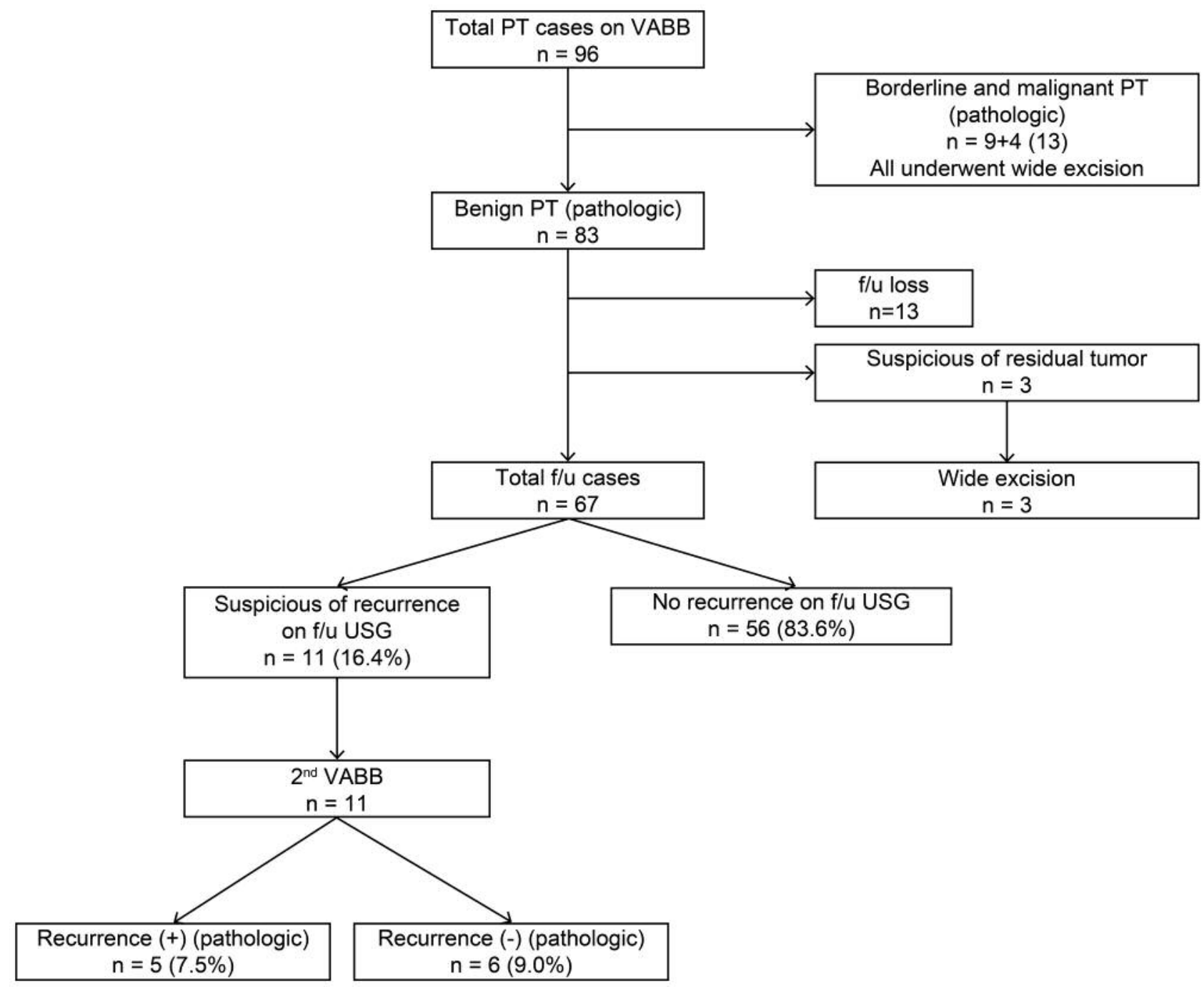

Figure 1. Flowchart illustrating the selection process of the study population. PT: Phyllodes tumor; USG: ultrasonography; VABB: vacuum-assisted breast biopsy.

were found to be benign PTs on pathology. None of these 5 cases recurred again, and no distant metastases were detected during subsequent follow-up periods.

\section{Discussion}

PT is classified either as benign, borderline, or malignant based on its margin, stromal cell density, mitotic count, and heterogeneity. The frequency of malignant PTs reported by other investigators ranges from 2-45\% (14-16); these differences may be explained by tumor heterogeneity, errors during sample collection, and different standards for interpreting histological results. Histological examination is considered necessary for fast-growing tumors, even those that appear benign, because they are more likely to be PTs that require surgery than fibroadenomas $(5,6)$. PT diagnosis via $\mathrm{CNB}$ leads to wide local excision, including at least $1 \mathrm{~cm}$ of the normal surrounding tissue. However, if the tumor is suspected to be a fibroadenoma on US but subsequently diagnosed as a benign PT on post-biopsy histopathological examinations, routine follow-up without surgery may be feasible (17). Reinfuss et al. (18) reported a local recurrence rate of $4 \%$ and a 5-year survival rate of $96 \%$ when using this follow-up method in benign PT patients; however, whether surgery or surveillance is the best option remains unclear.

VABB, which has been widely used for the diagnosis and treatment of breast diseases, is a minimally invasive biopsy method that removes breast lesions under US guidance without retargeting or reinsertion. Although VABB was initially developed for diagnostic purposes, it is now widely 
Table I. Characteristics of patients diagnosed with phyllodes tumors by ultrasonography guided vacuum-assisted breast biopsy.

\begin{tabular}{|c|c|c|c|c|c|c|}
\hline Variable & Category & $\begin{array}{c}\text { Total PT cases, } \\
\mathrm{n}=96(\%)\end{array}$ & $\begin{array}{c}\text { Benign PT cases, } \\
\mathrm{n}=83(\%)\end{array}$ & $\begin{array}{c}\text { Borderline PT cases } \\
n=9(\%)\end{array}$ & $\begin{array}{c}\text { Malignant PT cases, } \\
n=4(\%)\end{array}$ & $p$-Value \\
\hline \multirow[t]{6}{*}{ Age, years $(\mathrm{N}=87)$} & $10-19$ & $4(4.6)$ & $4(5.3)$ & 0 & 0 & \\
\hline & $20-29$ & $35(40.2)$ & $32(42.1)$ & $2(22.2)$ & $1(25.0)$ & \\
\hline & $30-39$ & $30(32.2)$ & $26(34.2)$ & $3(33.3)$ & $1(25.0)$ & \\
\hline & $40-49$ & $15(17.2)$ & $12(15.8)$ & $2(22.2)$ & $1(25.0)$ & \\
\hline & $\geq 50$ & $5(5.7)$ & $2(2.6)$ & $2(22.2)$ & $1(25.0)$ & \\
\hline & Mean \pm SD & $32 \pm 9.8$ & $30 \pm 9.0$ & $39 \pm 12.1$ & $39 \pm 13.8$ & 0.050 \\
\hline \multirow[t]{6}{*}{ Lesion size, $\mathrm{cm}(\mathrm{n}=96)$} & $\leq 1.0$ & $10(10.4)$ & $10(12.0)$ & 0 & 0 & \\
\hline & $1.1-2.0$ & $47(49.0)$ & $41(49.4)$ & $4(44.4)$ & $2(50.0)$ & \\
\hline & $2.1-3.0$ & $26(27.1)$ & $22(26.5)$ & $4(44.4)$ & 0 & \\
\hline & $3.1-4.0$ & $8(8.3)$ & $8(9.6)$ & 0 & 0 & \\
\hline & $\geq 4.0$ & $5(5.2)$ & $2(2.4)$ & $1(11.1)$ & $2(50.0)$ & \\
\hline & Mean \pm SD & $2.07 \pm 1.06$ & $1.97 \pm 0.84$ & $2.32 \pm 1.28$ & $3.63 \pm 2.81$ & 0.575 \\
\hline \multirow{7}{*}{$\begin{array}{l}\text { Physical examination } \\
(\mathrm{n}=96) \\
\text { BI-RADS category } \\
(\mathrm{n}=96)\end{array}$} & Palpable & $67(69.8)$ & $60(72.3)$ & $5(55.5)$ & $2(50.0)$ & \\
\hline & Non-palpable & $29(30.2)$ & $23(27.7)$ & $4(44.4)$ & $2(50.0)$ & 0.153 \\
\hline & 3 & $39(40.6)$ & $34(41.0)$ & $3(33.3)$ & $2(50.0)$ & \\
\hline & $4 \mathrm{a}$ & $52(54.2)$ & $46(55.4)$ & $6(66.6)$ & 0 & \\
\hline & $4 \mathrm{~b}$ & $2(2.1)$ & $1(1.2)$ & 0 & $1(25.0)$ & \\
\hline & $4 \mathrm{c}$ & $3(3.1)$ & $2(2.4)$ & 0 & $1(25.0)$ & \\
\hline & 5 & 0 & 0 & 0 & 0 & 0.097 \\
\hline
\end{tabular}

SD: Standard deviation; PT: phyllodes tumor; N: number of patients; BI-RADS: 'Breast Imaging Reporting and Data System'.

used to excise tumors presumed to be benign. The scope of its use has expanded to include many benign breast diseases such as fibroadenoma, intraductal papilloma, breast abscess, and gynecomastia. VABB is reportedly sufficient to treat benign tumors of $3 \mathrm{~cm}$ or less through complete excision $(12,13)$.

Only $0.86 \%$ of the breast lesions diagnosed using VABB at our institution were PTs, which is consistent with previously published incidence rates $(2,19)$. Because we chose VABB over routine FNA or CNB for category 3 or $4 \mathrm{~A}$ tumors $\leq 2 \mathrm{~cm}$ in diameter, it was unknown whether these lesions were PTs prior to performing VABB. Even if CNB was performed on breast lesions, definitively distinguishing PT from fibroadenoma would be challenging, and previous studies have found false negative rates of $8-39 \%$ for PT diagnoses using CNB (20-22). Among the 96 lesions diagnosed as PT through VABB in our study, FNA or CNB had been previously performed in 16 lesions; 14 of which had been diagnosed as other benign diseases such as fibroadenoma, and 2 had been found to be benign PT. While we routinely performed partial mastectomy for tumors diagnosed as PT by CNB, VABB was performed in 2 cases because of the tumors' small sizes $(<2 \mathrm{~cm})$ even though they were suspected to be benign PTs.

The average age of onset for PT is reportedly 45 years, which is 20 years older than that for fibroadenoma (23). PT is also reported to be rare during adolescence $(24,25)$ and is more common in Caucasians and Latin Americas (26) or in East Asians (15). However, the mean age of patients with PTs in our study was 32 years, with $77 \%$ aged between $10-39$ years. This is a younger age distribution than previously reported. The mean ages of patients diagnosed with benign, borderline, and malignant PTs were 30, 39, and 39 years, respectively; hence, patients diagnosed with benign PT were slightly younger.

Clearly distinguishing benign and malignant tumors through mammography or US examination is challenging. PTs appear as segmented entities with a clear, smooth margin resembling fibroadenoma on radiological images, and show a clear, smooth margin containing a cyst or homogeneous interior echo on US (27). Likewise, when we analyzed preoperative US findings for lesions diagnosed as PT, 39 lesions were BIRADS category 3 (40.6\%) and 57 were category 4 (59.4\%). This indicated that PTs are often diagnosed as category 3 lesions, demonstrating the difficulty in differentiating PTs from other breast diseases before performing histological examinations. No correlations were also found between histological results and BI-RADS US categories for benign, borderline, or malignant PTs. In particular, borderline and malignant PTs showed high frequencies of category 3 lesions (38.7\% and $40 \%$, respectively), which were not different from that of benign PT $(38.8 \%)$.

Clinically, PTs present as fast-growing benign breast mass lesions that can sometimes grow slowly for several years before rapidly enlarging. Compared to their benign counterparts, malignant PTs exhibit faster growth rates and larger sizes, with tumors $\geq 20 \mathrm{~cm}$ reported fairly often. However, these clinical characteristics are not sufficient to 
Park et al: Phyllodes Tumors Diagnosed by Ultrasound-guided VABB

Table II. Comparison between the characteristics of the recurred and non-recurred patients with benign phyllodes tumors post-VABB.

\begin{tabular}{|c|c|c|c|c|c|}
\hline Variable & Category & $\begin{array}{c}\text { Total benign PT } \\
\text { Followed up with USG, } \mathrm{n}=67(\%)\end{array}$ & $\begin{array}{l}\text { Non-recurrence } \\
\text { group, } \mathrm{n}=62(\%)\end{array}$ & $\begin{array}{c}\text { Recurrence group, } \\
\mathrm{n}=5(\%)\end{array}$ & $p$-Value \\
\hline \multirow{6}{*}{ Age, years $(\mathrm{N}=61)$} & $10-19$ & $4(6.6)$ & $4(7.1)$ & 0 & \\
\hline & $20-29$ & $25(41.0)$ & $21(37.5)$ & $4(80.0)$ & \\
\hline & $30-39$ & $23(37.7)$ & $22(39.3)$ & $1(20.0)$ & \\
\hline & $40-49$ & $9(14.8)$ & $9(16.1)$ & 0 & \\
\hline & $\geq 50$ & 0 & 0 & 0 & \\
\hline & Mean \pm SD & $30 \pm 7.8$ & $30 \pm 7.8$ & $25 \pm 7.0$ & 0.192 \\
\hline \multirow{6}{*}{$\begin{array}{l}\text { Lesion size, } \mathrm{cm} \\
(\mathrm{n}=67)\end{array}$} & $\leq 1.0$ & $8(11.9)$ & $8(12.9)$ & 0 & \\
\hline & $1.1-2.0$ & $34(50.7)$ & $32(51.6)$ & $2(40.0)$ & \\
\hline & $2.1-3.0$ & $16(23.9)$ & $16(25.8)$ & 0 & \\
\hline & $3.1-4.0$ & $8(11.9)$ & $6(9.7)$ & $2(40.0)$ & \\
\hline & $\geq 4.0$ & $1(1.5)$ & 0 & $1(20.0)$ & \\
\hline & Mean \pm SD & $1.95 \pm 0.81$ & $1.87 \pm 0.72$ & $3.00 \pm 1.14$ & 0.002 \\
\hline \multirow{7}{*}{$\begin{array}{l}\text { Physical examination } \\
(\mathrm{n}=67) \\
\text { BI-RADS USG category } \\
(\mathrm{n}=67)\end{array}$} & Palpable & $45(67.2)$ & $40(64.5)$ & $5(100)$ & \\
\hline & Non-palpable & $22(32.8)$ & $22(35.5)$ & 0 & 0.163 \\
\hline & 3 & $26(38.8)$ & $24(38.7)$ & $2(40.0)$ & \\
\hline & $4 \mathrm{a}$ & $39(58.2)$ & $36(58.1)$ & $3(60.0)$ & \\
\hline & $4 \mathrm{~b}$ & $1(1.5)$ & $1(1.6)$ & 0 & \\
\hline & $4 \mathrm{c}$ & $1(1.5)$ & $1(1.6)$ & 0 & \\
\hline & 5 & 0 & 0 & 0 & 1.000 \\
\hline
\end{tabular}

VABB: Vacuum-assisted breast biopsy; SD: standard deviation; USG: ultrasonography; PT: phyllodes tumor; N: number of patients; BI-RADS: 'Breast Imaging Reporting and Data System'.

Table III. Patient and tumor characteristics in the 5 recurred cases after VABB.

\begin{tabular}{|c|c|c|c|c|c|c|c|c|}
\hline Patient & Age & $\begin{array}{l}\text { Family } \\
\text { history }\end{array}$ & $\begin{array}{l}\text { Tumor size, } \\
\mathrm{cm} \text {, location }\end{array}$ & $\begin{array}{l}\text { BI-RADS } \\
\text { category }\end{array}$ & $\begin{array}{l}\text { Interval to } \\
\text { recurrence, mo }\end{array}$ & $\begin{array}{l}\text { Recurrent tumor } \\
\text { size, } \mathrm{cm}\end{array}$ & $\begin{array}{l}\text { BI-RADS category } \\
\text { for recurrence }\end{array}$ & $\begin{array}{l}\text { Final diagnosi } \\
\text { for recurrence }\end{array}$ \\
\hline 1 & 20 & None & 4.76, RUO & $4 a$ & 5 & 0.87 & $4 \mathrm{a}$ & Benign \\
\hline 2 & 21 & None & 3.06, RLI & 3 & 4 & 1.43 & 3 & Benign \\
\hline 3 & 22 & None & 1.98, LUI & $4 a$ & 31 & 2.41 & $4 a$ & Benign \\
\hline 4 & 26 & None & 2.00, LUO & 3 & 20 & 2.31 & $4 a$ & Benign \\
\hline 5 & 37 & None & 3.20, RUO & $4 a$ & 6 & 1.66 & $4 a$ & Benign \\
\hline
\end{tabular}

VABB: Vacuum-assisted breast biopsy; RUO: right upper outer; RLI: right lower inner, LUI: left upper inner; LUO: left upper outer; BI-RADS: 'Breast Imaging Reporting and Data System'.

differentiate malignant and benign tumors $(16,28)$. In our study, $59.4 \%$ of the PTs were $2 \mathrm{~cm}$ or smaller; their mean size was $2.07 \mathrm{~cm}$, and only $13.5 \%$ were $3 \mathrm{~cm}$ or larger. Our data suggested that malignant tumors are slightly larger than benign and borderline tumors. Previous reports of PT published to date showed mean tumor sizes of 3.7-8.0 cm, which are larger than that observed in our study (14-16). Even if large tumors $\geq 3 \mathrm{~cm}$ can be excised using the VABB system, it is difficult to confirm complete excision with a negative margin. Moreover, due to the possibility of malignant PT, wide local excision appears to be a more valid method for reducing local recurrence than VABB for lesions that are suspected PTs based on cytology or CNB.
We were usually undecided whether benign PTs diagnosed through VABB should undergo further excision surgery. However, most patients preferred follow-up surveillance. Moreover, many VABB procedures conducted to date have shown a high rate of complete excision; only $5 \%$ of cases in our previous studies showed residual tumor tissue on followup US examinations conducted every 3-6 months $(12,13)$. Therefore, we determined that further wide local excision surgery for PT would be performed only when recurrence was identified during follow-up, and thus implemented a watchand-wait program rather than immediate repeat surgery.

Local PT recurrence rates reportedly range between $10 \%$ to $40 \%$, with an average of $15 \%$ (14-16). Shaaban et al. observed 
recurrences in 112 of 1,052 surgically excised cases of benign PT across 12 studies, with an average recurrence rate of $11 \%$ (range $=0-43 \%$ ). While the frequency of postoperative margin involvement was $7.6-43.7 \%$, the recurrence rate was relatively low. Moreover, tumors excised with $10 \mathrm{~mm}$ versus $1 \mathrm{~mm}$ margins showed no significant differences in recurrence rates (7.9\% vs. 5.7\%, respectively) (29). Not many studies have reported recurrence rates after follow-up without additional surgery in cases of benign PT diagnosed through VABB. In a study by Quyang et al., who examined 108 cases of benign PT diagnosed through VABB, recurrence was identified in 12 cases (11.1\%) during an average of 21.8 months of follow-up without additional surgery. Compared to previous studies, our recurrence rate of $5.7 \%$ was relatively low; considering that our follow-up period was longer than in other studies, it can be concluded that the outcomes in our patients were more favorable.

Local recurrence is usually related to the extent of the initial surgery $(16,30-32)$. Recurrence usually occurs during the first few postoperative years and resembles the original tumor in its histological presentation $(16,28)$, although recurrent tumors will often show more aggressive histological characteristics than the original lesion (33). However, the 5 cases of recurrence in our study were all confirmed histologically to be benign PT.

In most cases, there is no association between local recurrence and distant metastasis; the latter can occur without the former (34). Even in rare cases of persistent recurrence over a long period of time, no differences in survival rate were observed. Moreover, local recurrence is reportedly unrelated to the PT's histological characteristics or margin status (35). While age has been found to be of little importance as a recurrence factor, it was suggested that recurrences in adolescents may be slightly less aggressive $(24,25)$.

The mean age of patients with benign PTs who experienced recurrences was 25 years, which was younger than that in the non-recurrence group (30 years). Our data also revealed that older patients were more likely to be diagnosed with malignant PT, while benign PT showed a higher rate of local recurrence in younger patients. Although the relationship between original tumor size and recurrence rate is unclear, most studies have reported a lower frequency of local recurrence for tumors $\leq 2 \mathrm{~cm}(16,36-38)$, although certain studies found tumor size not to influence recurrence $(18,28)$. In our study, the mean tumor size in the recurrence group was $3.0 \mathrm{~cm}$, which was significantly larger than that in the non-recurrence group $(1.87 \mathrm{~cm})$. Ultimately, it is easier to completely excise smaller tumors through VABB to ensure a negative resection margin; meanwhile, there is a high possibility of incomplete excision of larger tumors using $\mathrm{VABB}$, resulting in a higher local recurrence rate.

In conclusion, our study showed that the local recurrence rate of benign PTs diagnosed via VABB is low even when US-based surveillance is employed instead of immediate surgical excision. Additionally, histological analysis of recurrent tumors showed no malignant transformations, indicating no need for immediate surgery for benign PTs diagnosed through VABB unless residual tumor tissue is found upon US examination after 3 months post-VABB. Instead, the patient should be carefully monitored, and additional excisional biopsy or VABB can be performed if recurrence is detected during follow-up. Studies with longerterm follow-up periods are currently being planned.

\section{Conflicts of Interest}

The Authors declare that they have no competing interests.

\section{References}

1 Feuer EJ, Wun LM, Boring CC, Flanders WD, Timmel MJ and Tong T: The lifetimes risk of developing breast cancer. J Ned Cancer Inst 85: 892-897, 1993.

2 Buchanan EB: Cystosarcoma phyllodes and its surgical management. Am Surg 61: 350-355, 1995.

3 Muller J: Uber den feineren Ban and Die Formen der Krankaften Geschwulste. Berlin G Reiner 1: 54-57, 1838.

4 World Health Organization: Histological typing breast tumor. Tumori 68: 181-198, 1982.

5 Khan SA and Badves S: Phyllodes tumors of the breast. Curr Treat Options Oncol 2: 139-147, 2001.

6 Joshi SC, Sharma DN, Bahadur AK, Maurya R, Kumar S and Khurana N: Cystosarcoma phyllodes: our institutional experience. Australas Radiol 47: 434-437, 2003.

7 Parker SJ and Harries SA: Phyllodes tumours. Postgrad Med J 77: 428-435, 2001

8 Deeming G, Divakaran R, Butterworth D and Foster M: Temporomandibular region metastasis from cystosarcoma phyllodes. A case report and review of the literature. J Craniomaxillofac Surg 31: 325-328, 2003.

9 Guerrero MA, Ballard BR and Grau AM: Malignant phyllodes tumor of the breast: review of the literature and case report of stromal overgrowth. Surg Oncol 12: 27-37, 2003.

10 Inoshita S: Phyllodes tumor (cystosarcoma phyllodes) of the breast: a clinicopatholopgic study of 45 cases. Acta Pathol Jpn 38: 21-33, 1988.

11 Shabahang M, Franceschi D, Sundaram M, Castillo MH, Moffat FL, Frank DS, Rosenberg ER, Bullock KE and Livingstone AS: Surgical management of primary breast sarcoma. Am Surg 68: 673-677, 2002.

12 Park HL, Kim KY, Park JS, Shin JE, Kim HR,Yang B, Kim JY, Shim JY, Shin EA and Noh SM: Clinicopathologic analysis of ultrasound-guided vacuum-assisted breast biopsy for the diagnosis and treatment of breast disease. Anticancer Res 38 : 2455-2462, 2018.

13 Park HL, Kwak JY, Jung HK, Lee SH, Shim JY, Kim JY and Lee KS: Is mammotome excision feasible for benign breast mass bigger than $3 \mathrm{~cm}$ in greatest dimension? J Kor Surg Soc 70: 2529, 2006.

14 Bennett IC, Khan A. DeFrreitas R, Chaudary MA and Millis RR: Phyllodes tumours: a clinicopathological review of 30 cases. Aust N Z J Surg 62: 628-633, 1992. 
15 Chua CL, Thomas A and Ng BK: Cystosarcoma phyllode; a review of surgical options. Surgery 105: 141-147, 1989.

16 Ciatto S, Bonardi R, Cataliotti L and Cardona G: Phyllodes tumor of the breast: a multicenter series of 59 cases. Eur J Surg Oncol 18: 545-549, 1992.

17 Zurrida S, Bartoli C, Galimberti V, Squicciarini P, Delledonne V, Veronesi P, Bono A, de Palo G and Salvadori B: What therapy for unexpected phyllodes tumour of the breast? Eur J Cancer 28: 654-657, 1992.

18 Reinfuss M, Mituś J, Duda K, Stelmach A, Ryś J and Smolak K: The treatment and prognosis of patients with phylllodes tumor of the breast. Cancer 77: 910-916, 1996.

19 Dyer NH, Bridger JE and Taylor RS: Cystosarcoma phylloides. Br J Surg 53: 450-455, 1966.

20 Bode MK, Rissanen T and Apaja-Sarkkinen M: Ultrasonography and core needle biopsy in the differential diagnosis of fibroadenoma and tumor phyllodes. Acta Radiol 48: 708-713, 2007.

21 Choi J and Koo JS: Comparative study of histologic features between core needle biopsy and surgical excision in phyllodes tumor. Pathol Int 62: 120-126, 2012.

22 Dillon MF, Quinn CM, McDermott EW, O'Doherty A, O'Higgins $\mathrm{N}$ and Hill AD: Needle core biopsy in the diagnosis of phyllodes neoplasm. Surgery 140: 779-784, 2006.

23 Oberman HA: Cystosarcoma phyllodes. a clinicopathologic study of hypercellular periductal stromal neoplasm of the breast. Cancer 18: 697-710, 1965.

24 Amerson JR: Cystosarcoma in adolescent females. Ann Surg 171: 849-858, 1970.

25 Adachi Y, Matsushima T, Kido Am Shimono R, Adachi E, Matsukuma A, Mori K and Sugimachi K: Phyllodes tumor in adolescents. Report of two cases and review of the literature. Breast Dis 6: 285-293, 1993.

26 Bernstein L, Deapen D and Ross RK: The descriptive epidemiology of malignant cystosarcoma phyllodes tumors of the breast. Cancer 71: 3020-3024, 1993.

27 Buchburger W, Strasser K, Heim K, Müller E and Schröcksnadel $\mathrm{H}$ : Phyllodes tumor: findings on mammography, sonography and aspiration cytology in 10 cases. AJR Am J Roentol 157: 715719, 1991
28 Stebbing JF and Nash AG: Diagnosis and management of phyllodes tumor of the breast: experience of 33 cases at a specialist centre. Ann R Coll Surg Engl 77: 181-184, 1995.

29 Shaaban M and Barthelmes L: Benign phyllodes tumours of the breast: (Over) treatment of margins - A literature review. Eur J Surg Oncol 43: 1186-1190, 2017.

30 Pietruszka $\mathrm{M}$ and Barnes L: Cystosarcoma phyllodes. a clinocopathological analysis of 42 cases. Cancer 41: 1974-1983, 1978.

31 Ward RM and Evans HL: Cystosarcoma phyllodes. a clinocopathologic study of 26 cases. Cancer 58: 2282-2289, 1986.

32 Hart WR, Bauer RC and Oberman HA: Cystosarcoma phyllodes. A clinocopathologic study of twenty-six hypercellular periductal stromal tumors of the breast. Am J Clin Pathol 70: 211-216, 1978.

33 Moffat CJ, Pinder SE, Dixon AR, Elston CW, Blamey RW and Ellis IO: Phyllodes tumour of the breast: a clinicopathological review of the thirty-two cases. Histopathology 27: 205-218, 1995.

34 Cohn-Cedermark G, Rutqvist LE, Rosendahl I and Silfverswärd C: Prognostic factors in cystosarcoma phyllodes. A clinocopathologic study of 77 patients. Cancer 68: 2017-2022, 1991.

35 Palmer ML, De Risi DC, Pelikan A, Patel J, Nemoto T, Rosner D and Dao TL: Treatment options and recurrence potential for cystosarcoma phyllodes. Surg Gynecol Obstet 170: 193-196, 1990.

36 Bartoli C, Zurrida S, Verinesi P, Bono A, Chiesa F, Cosmacini P and Clemente C: Small sized phyllodes tumor of the breast. Eur J Surg Oncol 16: 215-219, 1990.

37 Park HL, Kwon SH, Chang SY, Huh JY, Kim JY, Shim JY and Lee YH: Long-term follow-up result of benign phyllodes tumor of the breast diagnosed and excised by ultrasound-guided vacuumassisted breast biopsy. J Breast Cancer 15: 224-229, 2012.

38 Park HL, Kim KY, Park JS, Shin JE, Kim HR, Yang B, Kim JY, Shim JY, Shin EA and Noh SM: Clinicopathological analysis of ultrasound-guided vacuum-assisted breast biopsy for the diagnosis and treatment of breast disease. Anticancer Res 38 : 2455-2462, 2018.

Received July 2, 2018

Revised July 16, 2018

Accepted July 17, 2018 